ORIGINAL

\title{
Cariotipo de Espeletiopsis muiska
}

\author{
Karyotype of Espeletiopsis muiska
}

\author{
Héctor Rondón $B,{ }^{1}$ Biol, Leidy Rache $C,{ }^{2 *}$ M.Sc, José Pacheco M, ${ }^{1}$ Ph.D.
}

\begin{abstract}
${ }^{1}$ Universidad Pedagógica y Tecnológica de Colombia. Escuela de Ciencias Biológicas. Laboratorio BIOPLASMA. Tunja, Colombia. 'Universidad de los Andes. Bogotá D.C. Colombia. *Correspondencia: leidyrache@gmail.com
\end{abstract}

Recibido: Febrero de 2012; Aceptado: Abril de 2013.

\section{RESUMEN}

Objetivo. Estudiar el ciclo celular y realizar la descripción cromosómica de Espeletiopsis muiska, utilizando células meristemáticas de ápices radicales obtenidos a través de cultivo in vitro de embriones en medio MS suplementado con AIB. Materiales y métodos. Se colectaron ápices radicales a diferentes horas del día y se contaron en ellos las células presentes en cada fase mitótica, se determinó la duración del ciclo celular y la hora de mayor actividad mitótica. La descripción de los cromosomas y la elaboración del cariotipo de la especie, se realizó utilizando un protocolo que permitió la obtención de cromosomas metafásicos. Resultados. Respecto a la duración del ciclo celular, se encontró que la interfase comprende el $94.65 \%$ y la mitosis el $5.35 \%$ del total del ciclo celular. Entre las fases mitóticas la profase tiene mayor duración, $1.92 \%$, mientras que la anafase es la más corta, $0.96 \%$. En cuanto a la hora mitótica, las células meristemáticas de los ápices radicales presentaron mayor actividad entre las $10: 30$ y las $11: 15$. Con el estudio citogenético se encontraron 19 pares de cromosomas con longitudes e índices centroméricos similares y cariotipo asimétrico. Conclusiones. El estudio detallado de los cromosomas, permitió determinar un complemento cromosómico $2 n=38+2 B$, dos cromosomas con microsatélites terminales y uno con constricción secundaria.

Palabras clave: Cromosomas, mitosis, páramo, raíces (Fuente: CAB).

\section{ABSTRACT}

Objective. The cell cycle and chromosomic description of Espeletiopsis muiska was studied in meristematic cells of root tips obtained from in vitro culture of embryos on MS medium supplemented with IBA. Materials and methods. Root tips at different times of day were collected and the cells in each mitotic phase were counted. With this information, the cell cycle length and mitotic activity was determined at its peak hours. Description of chromosomes and elaboration of karyotype of the specie was done with a protocol that allows obtaining metaphase chromosomes. Results. Regarding the cell cycle length, we found that the interface includes the $94.65 \%$ and mitosis the $5.35 \%$ of total cell cycle. Regarding the mitotic phases, the prophase lasts longer, $1.92 \%$, while the anaphase is the shortest, $0.96 \%$. As to mitotic hour, meristematic cells of root tips showed an increased activity between 10:30 and 11:15. 19 pairs of chromosomes with similar lengths, similar centromeric indices and asymmetrical karyotype were found in this cytogenetic study. Conclusions. The detailed study of the chromosomes revealed a chromosome complement $2 n=38+2 B$, two chromosomes with microsatellite terminals and one with a secondary constriction.

Key words: Chromosomes, mitosis, moorland, roots (Source: $C A B$ ). 


\section{INTRODUCCIÓN}

El páramo es considerado un bioma reciente en el que se destacan los frailejones (1). En este bioma han sido escasos los estudios citogenéticos; uno de tales estudios es el que fue realizado en la tribu Heliantheae; en el cual se abordó el recuento cromosómico utilizando como material células sexuales; asimismo, la escasez de estudios en la subtribu Espeletiinae no ha permitido diferenciar citogenéticamente géneros con igual complemento cromosómico. Considerando que el conteo y la descripción cromosómica forman parte de la información básica de una especie o taxón, se hace notoria su ausencia en las descripciones generales y específicas del género Espeletiopsis.

El género Espeletiopsis fue propuesto por Cuatrecasas en 1976, con base en un grupo de 24 especies antes ubicadas en el género Espeletia Humb. \& Bonpl (2). Tales especies comparten como características comunes, el presentar inflorescencias corimboideo paniculadas y brácteas alternas en las ramas florales. Además, se caracterizan por presentar hojas más coriáceas y con menor cantidad de indumento, pero no muestran diferencias significativas en las secuencias de ADN, aparte de permitir con frecuencia la formación de híbridos intergenéricos, motivos por los cuales el estatus taxonómico de este grupo aún se discute y cabe la posibilidad de que en un futuro resulte más conveniente considerarlo como un subgénero, más que como un género independiente (3).

Para la subtribu Espeletiinae se han analizado siete géneros en los que se encuentra un número haploide sin variación de $n=19$ (4). Las técnicas citogenéticas son protocolos diseñados con el propósito de observar e identificar número, morfología y comportamiento de los cromosomas en la mitosis y meiosis; en plantas, el material de partida más utilizado son ápices de raíces y botones florales (anteras). Estos protocolos involucran cuatro etapas básicas: colecta, fijación, tinción y aplastamiento (squash); para el análisis de cromosomas mitóticos se realiza un paso adicional que implica un pretratamiento para detener las células en una fase del ciclo, correspondiente a la metafase ya que los cromosomas metafásicos pueden visualizarse mejor gracias al mayor grado de condensación que presentan.

Con el fin de contribuir al conocimiento del género Espeletiopsis, este trabajo tuvo como objetivo estudiar su ciclo celular y describir su cariotipo mediante la aplicación de diferentes técnicas citohistológicas.

\section{MATERIALES Y MÉTODOS}

Sitio de estudio. Las muestras se recolectaron en el parque natural "La Ranchería", sector pantano de ranchería, ubicado a 3200 msnm, con temperatura promedio de $11^{\circ} \mathrm{C}$ y humedad relativa de $67 \%$.

Muestra. Se seleccionaron plantas adultas de Espeletiopsis muiska y se tomaron aleatoriamente de 8 a 10 aquenios por ejemplar; posteriormente, en el Laboratorio de Cultivo de Tejidos Vegetales BIOPLASMA-UPTC se extrajeron las semillas de los aquenios y se cultivaron in vitro embriones en medio MS (5) con $3 \mathrm{mg} / \mathrm{L}$ de AIB (6). Para producir continuamente raíces se mantuvieron cultivos de brotes axilares con transferencia cada 45 días a MS con 1.0 y $2.0 \mathrm{mg} / \mathrm{L}$ de AIB. El pH de los medios de cultivo se ajustó a $5.7 \mathrm{con} \mathrm{HCl}$ $\mathrm{y} / \mathrm{o} \mathrm{KOH}$, los cultivos se incubaron a $24 \pm 1^{\circ} \mathrm{C}$ y fotoperíodo de 16 horas.

Determinación de la hora mitótica. La colecta de raíces se realizó durante un período comprendido entre las $7: 15$ y las 16:00, a intervalos de una hora, se mantuvieron 15 brotes enraizados in vitro, de cada uno se tomaron 3 raíces en crecimiento activo, de 1 a $2 \mathrm{~cm}$ de longitud y se escindieron los ápices radicales. Posteriormente, para confirmar la hora mitótica, se colectaron ápices radicales a las 9:40, 10:40 y 11:40. Los ápices escindidos se lavaron con agua y se refrigeraron a $4^{\circ} \mathrm{C}$ durante 24 horas en solución Farmer (Etanol 96\%: Ácido acético glacial en proporción 3:1, respectivamente, $6)$. Luego, los ápices se enjuagaron con agua y se colocaron en un portaobjetos con 2 gotas de orceina acética al $2 \%$ durante $10 \mathrm{~min}$; la preparación se flameó, sin permitir ebullición del colorante.

Para el aplastamiento y observación, se colocó el cubreobjetos sobre la muestra y con una barra de goma se propinó un golpe seco sobre los tejidos para disgregarlos y obtener células en un sólo plano; en seguida, se tomaron las dos placas, recubiertas en papel adsorbente, entre los dedos pulgar e índice y se presionó sin deslizar las láminas. Para la observación y conteo de las células que se encontraban en cada fase del ciclo celular se observó la zona meristemática con objetivo de $25 x$.

Los índices de fases parciales (IF) y el índice mitótico parcial (IM) se calcularon mediante las ecuaciones propuestas por Poggio y colaboradores (7):

IF = número de células en cada fase / número total de células $\times 100$ 
$\mathrm{IM}=\mathrm{IFp}+\mathrm{IFm}+\mathrm{IFa}+\mathrm{IFt}$

$\mathrm{p}=$ profase $; \mathrm{m}=$ metafase $; \mathrm{a}=$ anafase;

$\mathrm{t}=$ telofase.

El índice de fases totales (IFt) tiene en cuenta el promedio de los porcentajes de cada fase y el número de horas empleadas en el estudio; el índice mitótico total (IMt) se obtiene de la sumatoria de los índices de fase totales.

IFt $(\%)=\operatorname{IF}(\%) /$ número de horas

IMt $(\%)=$ IFp + IFm + IFa + IFt

Obtención de cromosomas metafásicos. De cada brote enraizado in vitro se tomaron de 10-15 ápices de 1 centímetro de longitud en crecimiento activo.

Para el pretratamiento se ensayaron dos agentes inhibidores del uso mitótico: colchicina y 8-hidroxiquinoleina (8). También se evaluó la acción de la colchicina disuelta en dimetilsulfoxido (DMSO), (9). Las variables evaluadas durante los pretratamientos se indican en la tabla 1.

Tabla 1. Pretratamientos para detener la mitosis en metafase.

\begin{tabular}{lccc}
\hline Mitodepresor & $\begin{array}{c}\text { Concentración } \\
(\%)\end{array}$ & $\begin{array}{c}\text { Tiempo de } \\
\text { exposición } \\
\text { (Horas) }\end{array}$ & $\begin{array}{c}\text { Temperatura } \\
\left({ }^{\circ} \mathbf{C}\right)\end{array}$ \\
\hline Colchicina & 0.05 & $3-6$ & \\
Colchicina-DMSO & 0.5 & $2-4$ & 2 y 20 \\
8-Hidroxiquinoleina & $0.002 \mathrm{M}$ & $1-5$ & \\
\hline
\end{tabular}

La efectividad de los pretratamientos se determinó mediante el índice de metafases (IMe):

$$
\mathrm{IMe}=\frac{\text { \# Total de células en división }}{\text { \# Total de células en metafase }} \times 100
$$

Después de pretratados los ápices con el agente mitodepresor, se enjuagaron con agua y se sumergieron en solución fijadora Farmer, luego se refrigeraron a $4^{\circ} \mathrm{C}$ durante 12 ó 24 horas.
Para degradar la pared celular, los ápices se trataron con soluciones ácidas, enzimáticas y ácido - enzimáticas, como se indica en la tabla 2. En la hidrólisis ácida fue necesario interrumpir el proceso mediante enjuague de las raíces con agua destilada. Para la hidrólisis enzimática se utilizaron recipientes obscuros para evitar la incidencia de la luz sobre la acción enzimática; además, se empleó como solvente tampón fosfato a pH de 5.8. En la hidrólisis ácido-enzimática, después del tratamiento con el ácido fue necesario elevar el pH de las raíces mediante inmersión en buffer fosfato con pH de 5.8, previo al tratamiento enzimático.

La selección del agente hidrolítico más efectivo se realizó observando la cantidad de restos celulares, presencia, digestión o ausencia de la pared celular, obtención de células individuales y dispersión de los cromosomas.

Una vez realizada la hidrólisis se evaluó la acción de cuatro tipos de coloración del ADN de la siguiente manera:

Orceina acética al $2 \%$ durante 10 - 30 minutos. Acetocarmín al $2 \%$ durante 15 min. Reactivo de Schiff durante 30 a 60 min. Doble tinción utilizando Reactivo de Schiff durante 45 minutos.

Posteriormente los ápices se enjuagaron y se llevaron a la placa porta objetos en la que previamente se mezcló una gota de ácido acético glacial al 45\% (v/v) con una gota de acetocarmín u orceina.

Finalizado cada procedimiento de tinción se retiró el exceso de colorante y se flameó la preparación. Luego se realizó el aplastamiento, siguiendo la metodología descrita para determinar la hora mitótica y se incluyó la utilización de barniz de uñas transparente para sellar la placa.

Elaboración del cariotipo. Siguiendo el procedimiento más efectivo para la obtención de cromosomas metafásicos, es decir en el que se obtuvo células individuales y mayor dispersión de los cromosomas, se analizaron 10 placas y se midió en cada cromosoma la longitud total y la de cada brazo, este proceso se realizó

Tabla 2. Agentes hidrolíticos empleados para degradar la pared celular.

\begin{tabular}{lcccc}
\hline \multicolumn{1}{c}{ Hidrólisis } & Agente Hidrolítico & Concentración & Temperatura oc Tiempo de exposición (min) \\
\hline Ácida (10) & $\mathrm{HCl}$ & $1 \mathrm{~N}$ & 60 & 19 \\
& Celulasa+Pectinasa & $2-4 ; 0.5-1(\%)$ & $10-20$ \\
Enzimática (11) & Celulasa+Pectinasa+ Macerozima & $2-3 ; 0.5-1 ; 1(\%)$ & 37 \\
Ácida -Enzimática (9) & $\mathrm{HCl}+$ Celulasa+Pectinasa+Macerozima & $1 \mathrm{~N}-2-4 ; 0,5-1 ; 0,5-1(\%)$ & 60 & 37 \\
\hline
\end{tabular}


manualmente, utilizando un micrómetro ocular y uno de platina, donde el valor de cada división del micrómetro ocular corresponde a $0.65 \mu \mathrm{m}$ con proyectivo de $20 x$ y objetivo $100 x$.

Con ayuda del objetivo de $100 x$ se realizó el conteo y descripción de los cromosomas. Los registros fotográficos se realizaron utilizando un microscopio Carl Zeiss, (Jena Jenamedz fluorescen), utilizando el objetivo de 100x con proyectivos de $16 x$ y $20 x$ y película en blanco y negro (asa 100). Los cromosomas se ordenaron teniendo en cuenta la longitud relativa, la topografía y el índice centromérico (IC), según la propuesta vigente de Levan et al (12).

IC $=\frac{\text { Longitud del brazo corto }(p)}{\text { Longitud total del cromosoma }}$

Con la siguiente categorización: metacéntrico IC $=50-37.5$, submetacéntrico IC $=37.4-25$, subtelocéntrico IC $=25-12.5$, telocéntrico IC $<12.5$.

Para determinar las diferencias entre el complemento cromosómico, se halló el índice de asimetría utilizado por Solis y Fernández (13).

\section{RESULTADOS}

Determinación de la hora mitótica. Ápices radicales de 1 a 3 centímetros de longitud son fácilmente manejables y colectarlos en las primeras etapas de crecimiento garantiza la presencia de un alto número de células en división dada la alta actividad metabólica en la zona meristemática.

En las células tratadas con fijador Farmer, por un período de 24 horas, y expuestas a una temperatura de $4^{\circ} \mathrm{C}$, se logró conservar las características físico-químicas y observar aclaramiento citoplasmático que se obtiene al precipitar componentes cromosómicos y citoplasmáticos. Estas condiciones facilitaron la obtención de un adecuado contraste cromatina/ citoplasma.

La tinción de cromatina con orceina acética durante 10 minutos fue un procedimiento rápido y efectivo para la coloración de ADN; además, el flameo de la muestra permitió eliminar el exceso de colorante en el citoplasma y aumentar el contraste con los cromosomas; mientras que un calentamiento excesivo de la muestra produce decoloración del preparado. Todo lo anterior permitió diferenciar claramente las etapas del ciclo celular y una observación más clara de los cromosomas.
El conteo de células en ápices radicales realizado a intervalos de una hora, inicialmente entre las 7:15 y las 16:00, indicó que el porcentaje de células en actividad mitótica entre las 7:15 y $12: 15$ oscila entre 5.5 y $7.8 \%$, presentándose el pico máximo a las $11: 15$; se observó un aumento progresivo desde las 9:15. En las horas de la tarde se evidenció una disminución del porcentaje de células en división (Figura 1A).

Durante la confirmación de los resultados anteriores, el conteo de células en división realizado a las 6:45 evidenció un bajo índice metafásico, los de las 9:40, 10:40 y 11:40 confirmaron la tendencia del aumento de células con actividad mitótica hacia las 9:30, y el pico máximo entre las 10:30 y $11: 15$ seguido de una disminución paulatina ratificada en el conteo realizado a las 17:00 (Figura $1 \mathrm{~B}$ ).

Por lo anterior, se puede deducir que la división celular en meristemos radicales de $E$. muiska se activó con el comienzo del fotoperíodo mediante
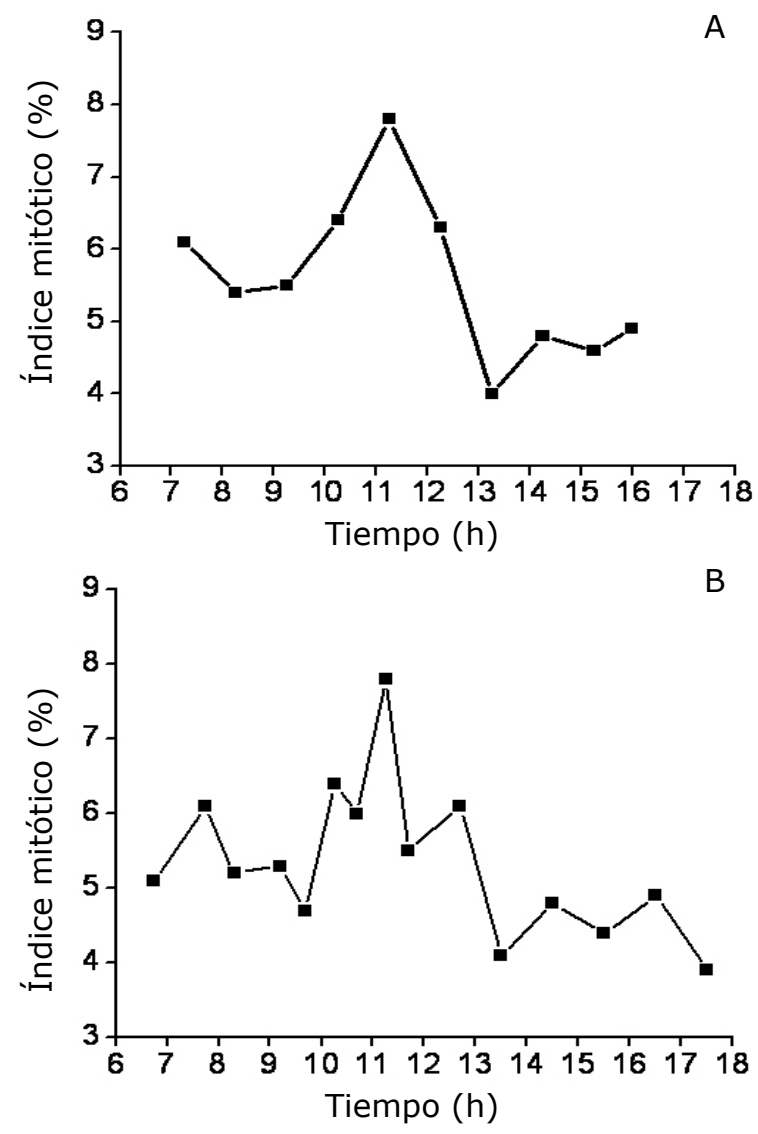

Figura 1. A. Variación del índice mitótico en ápices radicales de $E$. muiska a diferentes horas del día. B. Confirmación de los picos máximos de división celular en ápices radicales de $E$. muiska. 
estimulación de procesos físico-químicos o metabólicos. En este ensayo se determinó como período de mayor división celular el comprendido entre las $10: 30$ y 11:15.

El índice de fases del ciclo celular permitió determinar la cantidad de células por fase y con base en esta cantidad, se infirió su duración relativa en el ciclo celular. Los estadios mitóticos en $E$. muiska mostraron a la profase como el estado más largo, cuantificándose el mayor porcentaje de células, $1.92 \%$. En orden decreciente, se cuantificó el $1.44 \%$ de células en metafase, $1.03 \%$ en telofase y $0.96 \%$ en anafase; siendo esta última la más corta de la mitosis (Tabla 3). Finalmente, se observó 5.35\% de células en mitosis y $94.6 \%$ en interfase.

Tabla 3. Frecuencia de células en cada fase de mitosis e índices de fases totales en ápices radicales de E. muiska.

\begin{tabular}{ccccccc}
\hline Fases & Inter & Pro & Meta & Ana & Telo & Total \\
\hline $\begin{array}{c}\text { Células } \\
\text { observadas }\end{array}$ & 17613 & 373 & 263 & 176 & 190 & 18165 \\
Índice de fases & 94.6 & 1.92 & 1.44 & 0.96 & 1.03 & 100 \\
\hline
\end{tabular}

Si bien, el ciclo celular en E. muiska concuerda con las características reportadas para un ciclo celular normal, no obstante, en algunas anafases se hizo notoria la aparición de algunas estructuras que semejan puentes anafásicos.

Obtención de cromosomas metafásicos. La colecta de las raíces se hizo teniendo en cuenta la hora mitótica, 10:30 a 11:15. Las raíces muy delgadas fueron descartadas debido al fácil desprendimiento de la zona meristemática durante el proceso de hidrólisis.

En los ápices radicales tratados con colchicina a concentraciones de $0.05 \%$, durante 4 horas, se obtuvo un IMe $=34.3 \%$ y en los tratados con concentraciones de $0.5 \%$, durante el mismo tiempo, el porcentaje de células en metafase fue 47.7 (Tabla 4). Los resultados anteriores indican que el aumento en las concentraciones de colchicina es directamente proporcional al porcentaje de células detenidas en metafase.

Tabla 4. Índices de metafases en ápices radicales tratados con varios agentes mitodepresores.

\begin{tabular}{ccc}
\hline \hline Mitodepresores & Concentración (\%) & IMe (10\%) \\
\hline Colchicina & 0.05 & 34.3 \\
Colchicina - DMSO 2\% & 0.5 & 47.7 \\
8-hidroxiquinoleina & 0.25 & 54.6 \\
\hline
\end{tabular}

La utilización de colchicina en menores concentraciones, $0.25 \%$ y solubilizada en DMSO al $2 \%(\mathrm{p} / \mathrm{v})$, permitió aumentar el índice de metafases a $54.6 \%$ (Tabla 4).

Aunque tratar ápices radicales durante 4 horas con colchicina combinada con DMSO permitió conseguir el mayor índice de células detenidas en metafase no ocasionó una dispersión cromosómica adecuada. Al tratar células con 8-hidroxiquinoleina al $0.002 \mathrm{M}$ durante 5 horas se obtuvo un porcentaje de células metafásicas de $42.4 \%$, (Tabla 4) y una mayor separación de los cromosomas al inducir en éstos menor condensación, ocasionando así una mejor visualización de las constricciones secundarias, útiles en la identificación de cromosomas homólogos. De igual manera, se observó que las células de los ápices radicales tratadas con éste mitodepresor durante tiempos más cortos, disminuyeron la cantidad de cromosomas espiralizados correctamente, por lo que se infiere que interviene en la condensación de la cromatina.

Basados en lo anterior, y debido a la importancia de características como la dispersión y topografía de los cromosomas, para la elaboración del cariotipo se seleccionó el pretratamiento con 8-hidroxiquinoleina en concentración $0.002 \mathrm{M}$ y un tiempo de aplicación de 5 horas, como el mejor pretratamiento mitodepresor para la especie en estudio.

En los tejidos tratados con $\mathrm{HCl}, 1 \mathrm{~N}$ a $60^{\circ} \mathrm{C}$ durante 10 minutos, se observó ablandamiento; sin embargo, al efectuar el aplastamiento sólo se lograron liberar las células localizadas en la periferia, la mayoría de las cuales conservaron la lámina media impidiendo la liberación de grupos celulares en un sólo plano. Al aumentar el tiempo de exposición del tejido al agente hidrolítico, a 20 minutos, se presentó un alto deterioro del tejido haciéndose más difícil su manipulación.

En los tejidos tratados con concentraciones elevadas de enzimas se observó una alta degradación celular la cual ocasionó liberación de cromosomas; sin embargo, el grado de separación de los mismos no permite comprobar su pertenencia a una sola célula.

Mediante la hidrólisis ácida con $\mathrm{HCl} 1 \mathrm{~N}$ a $60^{\circ} \mathrm{C}$ durante 10 minutos se logró ablandar el tejido más no degradar totalmente la lámina media entre las células; con el uso de enzimas a $37^{\circ} \mathrm{C}$, durante 10 minutos, la pectinasa al $0.8 \%$ permitió degradar esta lámina al actuar directamente sobre las sales pépticas; con celulasa al $4 \%(\mathrm{p} / \mathrm{v})$ y macerozima al $1 \%(\mathrm{p} / \mathrm{v})$ que intervino como 
complemento enzimático, se logró degradar la celulosa, principal compuesto de la pared celular; lo anterior indica la importancia de la combinación de los agentes hidrolíticos dada la eficiencia de la acción enzimática sobre los tejidos previamente macerados con $\mathrm{HCl}$.

La presencia de la lámina media impide obtener células individuales y en una sola capa; además, la pared celular en E. muiska no permitió la dispersión cromosómica, por lo que fue necesario degradarla, con el fin de cambiar las condiciones físicas del interior celular, para facilitar la entrada de soluciones hipotónicas que intervinieron en el cambio de presión y en el desplazamiento de los cromosomas en el citoplasma.

En los ápices radicales la coloración con acetocarmín fue poco duradera, resultado apto para observación de fases celulares pero deficiente para la observación de cromosomas individuales. En cuanto a los ápices teñidos con orceina acética, se evidenció coloración intensa y duradera de la cromatina (4 días). La limitante de esta coloración en E. muiska fue su baja especificidad al teñir el citoplasma y los cromosomas reduciendo su contraste. El reactivo de Schiff permite visualizar con más detalle la topografía de los cromosomas debido a la alta especificidad entre la Fucsina y el grupo aldehído del ADN; sin embargo, en este ensayo, la tinción de la cromatina fue poco intensa.

Teniendo en cuenta las observaciones realizadas en los ápices radicales coloreados con orceina acética y reactivo de Schiff, se efectuó una doble tinción para conservar la coloración del ADN sin reducir el contraste núcleo/citoplasma; por tanto, se usó orceina acética durante 2 min, para evitar colorear el citoplasma y obtener en los cromosomas una coloración leve y duradera que luego fue intensificada mediante el empleo del reactivo de Schiff, obteniéndose una preparación apta para estudio citogenético.

Elaboración del cariotipo. Mediante observación de 30 células metafásicas de $E$. muiska se determinó que la especie posee un complemento cromosómico $2 n=38+2 B$ (Figura $2 \mathrm{~A}$ ); de los cuales 14 son metacéntricos $(m), 20$ submetacéntricos $(\mathrm{sm})$ y 4 subtelocéntricos (st); estos se distribuyeron en 19 pares de cromosomas que al presentar longitudes e índices centroméricos similares se agruparon de la siguiente manera: 1 a 7 metacéntricos, 8 a 17 submetacéntricos y 18 y 19 subtelocéntricos (Figura 2B y $\mathrm{C}$ ).

La longitud promedio de los cromosomas fue de $2.16 \mu \mathrm{m}$, con un rango desde $0.96 \mu \mathrm{m}$ (par 17) a $3.22 \mu \mathrm{m}$ (par 1),(Tabla 5). En uno de los
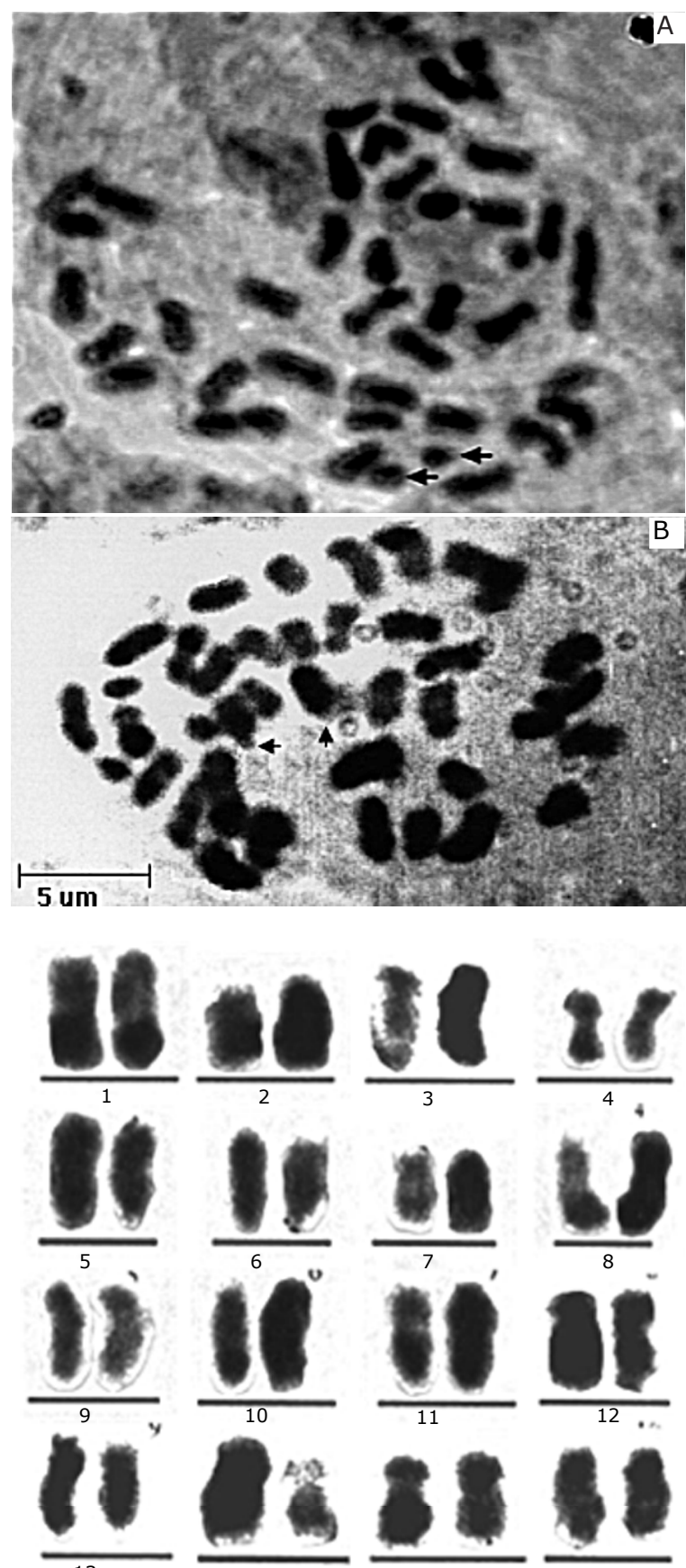

11

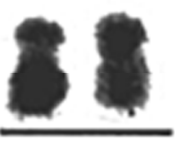

15

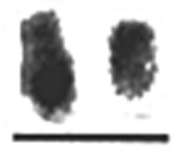

14

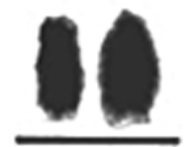

18

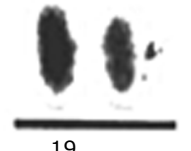

16

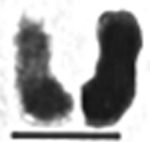

8
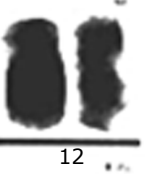

17

Figura 2. Cariotipo de Espeletiopsis muiska. Cuatrec. A. Con un complemento cromosómico $2 n=38+2 B$, las flechas indican los cromosomas B. B. Cromosomas metafásicos en célula meristemática radical; obsérvense los cromosomas portadores de microsatélite. C. Pares homólogos clasificados de acuerdo con la longitud total e índice centromérico. 
cromosomas del par sm número 13 , se observó una constricción secundaria sobre el brazo corto.

El índice centromérico presentó un valor promedio de 38.65 , lo que indica un mayor número de cromosomas metacéntricos; no obstante, se encontraron 10 pares submetacéntricos y 7 metacéntricos. Lo anterior se podría explicar por la diferencia de amplitud entre los intervalos del IC, 39.75 a 50.0 en pares metacéntricos y 26.89 a 33.33 en pares submetacéntricos (Tabla 5).

Tabla 5. Medidas de longitud de brazos, longitud total, relativa y proporción entre brazos e índice centromérico en cromosomas de ápices radicales de $E$. muiska.

\begin{tabular}{cccccccc}
\hline Par & $\mathbf{p}(\boldsymbol{\mu m})$ & $\mathbf{q}(\boldsymbol{\mu m})$ & $\mathbf{p}+\mathbf{q}(\boldsymbol{\mu m})$ & $\mathbf{L R}$ & $\mathbf{R B}$ & $\mathbf{I C}$ & Tipo \\
\hline 1 & 1.61 & 1.61 & 3.22 & 0.078 & 1.000 & 50 & $\mathrm{M}$ \\
2 & 0.96 & 1.61 & 2.58 & 0.062 & 1.677 & 37.2 & $M$ \\
3 & 0.96 & 1.93 & 2.58 & 0.062 & 2.010 & 37.2 & $M$ \\
4 & 0.96 & 1.29 & 2.25 & 0.054 & 1.343 & 42.66 & $M$ \\
5 & 0.96 & 1.29 & 2.25 & 0.054 & 1.343 & 42.66 & $M$ \\
$6 *$ & 0.64 & 0.97 & 1.61 & 0.039 & 1.515 & 39.75 & $M$ \\
7 & 0.64 & 0.97 & 1.61 & 0.039 & 1.515 & 39.75 & $M$ \\
8 & 0.64 & 1.74 & 2.38 & 0.057 & 2.718 & 26.89 & $\mathrm{Sm}$ \\
9 & 0.51 & 1.80 & 2.31 & 0.056 & 3.529 & 28.33 & $\mathrm{Sm}$ \\
10 & 0.77 & 1.48 & 2.25 & 0,054 & 1.922 & 34.22 & $\mathrm{Sm}$ \\
11 & 0.64 & 1.61 & 2.25 & 0.054 & 2.515 & 28.44 & $\mathrm{Sm}$ \\
12 & 0.64 & 1.61 & 2.25 & 0.054 & 2.515 & 28.44 & $\mathrm{Sm}$ \\
13 & 0.64 & 1.29 & 1.93 & 0.046 & 2.015 & 33.16 & $\mathrm{Sm}$ \\
14 & 0.64 & 1.29 & 1.93 & 0.046 & 2.015 & 33.16 & $\mathrm{Sm}$ \\
15 & 0.51 & 1.42 & 1.93 & 0.046 & 2.784 & 26.42 & $\mathrm{Sm}$ \\
16 & 0.64 & 1.16 & 1.80 & 0.043 & 1.812 & 35.55 & $\mathrm{Sm}$ \\
17 & 0.32 & 0.64 & 0.96 & 0.023 & 2.000 & 33.33 & $\mathrm{Sm}$ \\
18 & 0.64 & 1.91 & 2.58 & 0.062 & 2.984 & 24.80 & $\mathrm{St}$ \\
19 & 0.64 & 1.91 & 2.58 & 0.062 & 2.984 & 24.80 & $\mathrm{St}$ \\
& & & & & $\Sigma 41.25$ & \\
\hline
\end{tabular}

$\mathrm{LR}=$ longitud relativa, $\mathrm{RB}=$ proporción entre brazos, $\mathrm{IC}=$ índice centromérico, $\mathrm{m}=$ metacéntrico, $\mathrm{sm}=$ Submetacéntrico, $\mathrm{st}=$ subtelocéntrico. * Par cromosómico con satélite

Se observaron cambios en la distribución de la cromatina (Figura 3A); presencia de cromosomas con microsatélites terminales ubicados en el brazo largo del par metacéntrico número 6 . Es de anotar que los satélites no siempre fueron observados en los dos cromosomas homólogos.

En cuanto al índice de asimetría, el valor obtenido en cromosomas de E. muiska, 0.973, permite clasificar el cariotipo como asimétrico y resaltar las diferencias intracromosómicas manifestadas por la presencia de cromosomas metacéntricos, submetacéntricos y subtelocéntricos.

En cuanto a cromosomas $B$, en células de ápices radicales de $E$. muiska se encontraron 2 cromosomas $B$, en los cuales no fue posible la identificación clara de cromátidas o constricción primaria y su longitud fue inferior a una micra.

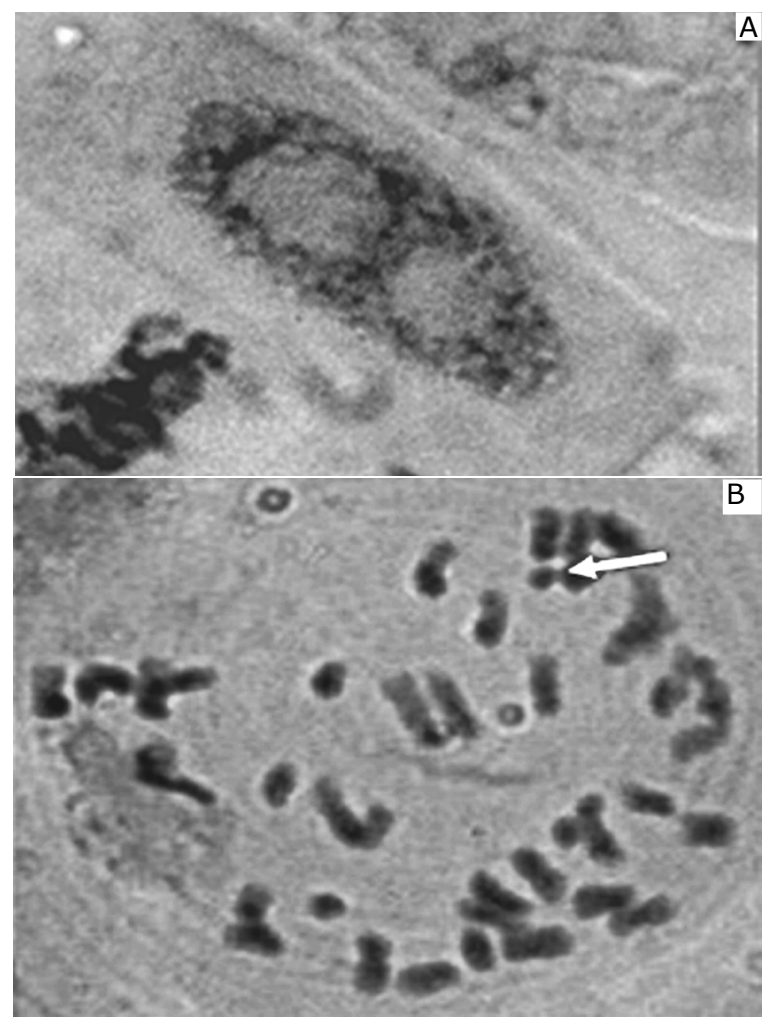

Figura 3. A. Núcleo interfásico de E. muiska con dos regiones de organización nucleolar. B. Cariotipo de E. muiska con un complemento cromosómico $2 \mathrm{n}=38+1 \mathrm{~B}$. La flecha indica la ubicación del cromosoma B. Fuente: autores.

Algunas de las células estudiadas presentaron un complemento cromosómico $2 \mathrm{n}=38+1 \mathrm{~B}$ (Figura 3B); esto se puede explicar debido a la falta de orientación de los cromosomas B en la anafase mitótica.

\section{DISCUSIÓN}

De acuerdo con Paniagua (14), las células de ápices radicales colectadas en las primeras etapas de crecimiento poseen un conjunto de características que las convierten en materia prima apropiada para estudios histológicos y citogenéticos. Asimismo, utilizar raíces delgadas facilita su tratamiento ya que en $E$. muiska estas tienden a lignificarse, perdiendo el aspecto translucido, y generando una exodermis observada en plantas de campo ya reportada para otros frailejones (15).

En el ensayo para identificar la hora mitótica, se determinó como período de mayor división celular el comprendido entre las 10:30 y 11:15 am; sin embargo, Alcorcés, 2001, Piña, 2001 en Ferrer et al (11), reportaron diferentes horas mitóticas que comprendían rangos entre las 5:30 y 10:30 para cinco especies de Tabebuia y 10:30 y 11:00 para la línea T-C-9-6 de fríjol. Alcorcés 
señala que la hora mitótica es un parámetro muy variable entre especies y dentro de éstas, es característico para cada especie y más aún para genotipos infraespecíficos, aunque eso no implica que especies diferentes no puedan tener la misma hora mitótica (11).

Los estadios mitóticos en $E$. muiska mostraron a la profase como el estadio más largo, cuantificándose el mayor porcentaje de células. De acuerdo con Sharma y Sharma, en Díaz et al (16), el encontrar mayor porcentaje de células en una fase se debe a la necesidad de un tiempo más largo para atravesarla. Después de la profase, los estadios que siguieron fueron la metafase, telofase y anafase, siendo esta última la más corta de la mitosis. Estos resultados concuerdan con Quispe et al (17) quienes reportan en Allium cepa datos semejantes.

Según Talledo et al, en Díaz et al (16), la mitosis ocupa del 10 al $14 \%$ del total del ciclo celular lo cual concuerda con lo reportado para plantas de Allium cepa con $\mathrm{IM}=11.26 \%$ y $14.58 \%$ (17); en $E$. muiska se observó el $5.35 \%$ de células en mitosis y el $94.6 \%$ en interfase; resultados similares fueron reportados por Rodríguez (9) en Physalis peruviana, con índice de $5.22 \%$; estas diferencias podrían explicarse por la alta variabilidad en cuanto al tiempo de duración de la mitosis en células de diferentes especies de plantas.

Respecto a la aparición de algunas estructuras que semejan puentes anafásicos en algunas anafases del ciclo celular en $E$. muiska, este fenómeno también ha sido reportado en raíces de Allium cepa por Carruyo et al (18), quienes observaron la formación de estructuras individuales y múltiples, aberraciones atribuidas a largos periodos de almacenamiento de las semillas en condiciones extremas, que afectaron negativamente su viabilidad; sin embargo, en este trabajo la incidencia de dicho fenómeno fue baja.

Al tratar los tejidos con $\mathrm{HCl} 5 \mathrm{~N}$ a temperatura ambiente, durante 15 minutos, parte de éstos permanecieron intactos y la otra fue totalmente degradada, contrario a lo obtenido por Iganci et al (19), en ensayos con ápices radicales de Allium cepa quienes obtuvieron excelentes resultados de hidrólisis al utilizar $\mathrm{HCl} 5 \mathrm{~N}$, bajo las mismas condiciones.

Gómez y Tapia (20) obtuvieron buenos resultados en la hidrólisis al tratar ápices radicales de Prosopis laevigata mediante el uso de diferentes concentraciones de celulasa y pectinasa; en este trabajo la combinación de Celulasa 3\%, Macerozima
$1 \%$ y Pectinasa $0 ., 8 \%$, a $37^{\circ} \mathrm{C}$, durante 20 minutos, permitió obtener células libres y en una sola capa; sin embargo, se observó la presencia de pared celular que limitó la dispersión de los cromosomas dentro de la célula.

En cuanto al índice de asimetría, utilizado por Solis y Fernández (13), el valor obtenido en cromosomas de E. muiska, 0.973 , permite clasificar el cariotipo como asimétrico y resaltar las diferencias intracromosómicas debidas a la presencia de cromosomas metacéntricos, submetacéntricos y subtelocéntricos.

En cuanto a cromosomas B, Seguel y Zuñiga (21) observaron 2 cromosomas B al estudiar ápices radicales en Lapageria rosea, concordando con nuestros resultados en células de ápices radicales de $E$. muiska, en los que también se encontraron 2 cromosomas $\mathrm{B}$.

Finalmente, el número cromosómico cuantificado en células somáticas de $E$. muiska concuerda con los reportados por Rauscher (4) para la subtribu Espeletiinae, en los que los recuentos en células germinales para siete géneros estudiados encontró un complemento cromosómico $n=19$ sin variaciones conocidas; tal resultado se puede asociar con el origen reciente de los hábitat de páramo indicando que la diversidad de la subtribu es también de origen reciente (4); sin embargo, este estudio no presenta información detallada de la morfología de los cromosomas ni reporta la presencia de cromosomas con satélites o de cromosomas B.

En conclusión las 10:30 y las 11:15 am es el tiempo en el cual los ápices radicales de $E$. muiska presentan mayor actividad en cuanto a división celular. El pretratamiento con hidroxiquinoleina $0.002 \mathrm{M}$, permitió una condensación correcta de la cromatina lo cual favoreció la visualización de constricciones cromosómicas. E. muiska posee un complemento cromosómico $2 \mathrm{n}=38+2 \mathrm{~B}$; el par cromosómico metacéntrico número 6 presenta un microsatélite en el brazo largo del cromosoma que podría corresponder con regiones de organización nucleolar y el par submetacéntrico número 13 presenta constricción secundaria en el brazo corto del cromosoma.

\section{Agradecimientos}

A la Universidad Pedagógica y Tecnológica de Colombia, sede Tunja y a los integrantes del Grupo de Investigación BIOPLASMA-UPTC. 


\section{REFERENCIAS}

1. Salinas C, Fuentes LS, Hernández L. Caracterización de los lepidópteros fitófagos asociados a la herbivoría de frailejones en la microcuenca de la quebrada Calostros del Parque Nacional Natural Chingaza. Rev Mutis 2013; 3(1):1-22.

2. Díaz PS, Rodríguez CV. Nuevas especies colombianas de Espeletiopsis Cuatrec. y de Espeletia Mutis Ex Humb. \& Bonpl. (Asteraceae, Heliantheae, Espeletiinae). Rev Acad Colomb Cienc 2010; 34(133):441-454.

3. Díaz S, Obando S. Una especie nueva de Espeletiopsis asteraceae, (heliantheae) de Colombia. Rev Acad Colomb Cienc 2004; 28 : 25-32.

4. Rauscher JT. Molecular phylogenetics of the Espeletia complex (Asteraceae): Evidence from NRDNA its sequences on the closest relatives of an Andean adaptive radiation. Amer J Bot 2002; 89(7):1074-1084.

5. Murashige T, Skoog F. A revised medium for rapid growth and bio-assays with tobacco tissue cultures. Physiol Plant 1962; 15:473-497.

6. Rache LY, Pacheco JM. Micropropagación de Espeletiopsis muiska (Cuatrecasas), frailejón del parque natural La Ranchería-Boyacá, Colombia. Agron Colomb 2009; 27(3):349-358.

7. Poggio L, Mudry MD, Papeschi AG, Mola LM, Greizerstein E. Citogenética. Argentina: Universidad de Buenos Aires. Departamento de ecología, genética y evolución. Facultad de ciencias Exactas y Naturales; 2006.

8. Baeza CM, Schrader O, Terrab A, Stuessy T, Rosas M, Ruiz E, et al. Recuentos cromosómicos en plantas que crecen en Chile. III. Gayana Bot 2007; 64(2):175-183.

9. Rodríguez N, Bueno ML, Perea DA. Estudio citogenético en Physalis peruviana L. "Uchuva" (Solanaceae). Acta Biol Col 2006; 11(2):33-43.

10. Delgado LM, Uribe $M L$, Marulanda ML. Estandarización de la técnica citogenética "Squash" para conteo de cromosomas mitóticos en Rubus glaucus Benth. Rev Sci Tech 2010; 17(46):74-79.
11. Ferrer HE, Alcorcés NC, Méndez JR. Determinación del ciclo mitótico de dos cultivares de Gossypium hirsutum L. y dos ecotipos de Gossypium barbadense L. Acta Biol Par 2007; 36(3-4):121-149.

12. Levan A, Fredga K, Sandberg A. Nomenclature for centromeric position on chromosomes. Hereditas 1964; 52:201-220.

13. Solis VG, Fernández A. Karyotypic studies in Turnera sidoides complex (Turneraceae, Leiocarpae). Amer J Bot 2002; 89: 551-558.

14. Paniagua GA. Citología e histología vegetal y animal. 4a edición. México: Mc Graw-Hill Interamericana; 2007.

15. Luque AR. Estructura primaria del sistema radical de Coespeletia cuatrec. Interciencia 2004; 29(1):13-18.

16. Díaz D, González D, Rache L, Pacheco J. Efecto citogenético de la colchicina sobre yemas vegetativas de Physalis peruviana L. Prosp Cient 2008; (4):27-40.

17. Quispe J, Saldaña J, Verde T, Valderrama S. Efectos del sorbato de potasio a diferentes concentraciones y tiempo de exposición sobre el ciclo celular y el material genético en meristemos radiculares de Allium cepa L. (cebolla). Rev Enc Cien Intern 2010; 7(1):71-78.

18. Carruyo I, Fernández $Y$, Marcano L, Montiel $X$, Torrealba Z. Efectos tóxicos inducidos por el plomo en meristemos radiculares de cebolla (Allium cepa). Bol Cen Invest Biol 2006; 40(3):311-326.

19. Iganci J, Bobrowski V, Heiden G, Stein V, Y Rocha B. Efeito do extratoaquoso de diferentes espécies de boldo sobre a germinação e índice mitótico de Allium cepa L. Arq Inst Biol 2006; 73:79-82.

20. Gómez-Acevedo S, Tapia-Pastrana F. Estudio genecológico en Prosopis laevigata, Acacia farnesiana y Acacia schaffneri (leguminosae). Darwiniana 2003; 41:47-54.

21. Seguel C, Zúñiga A. El cariotipo de Lapageria rosea R. (liliales: philesiaceae). Gayana Bot 2004; 61:76-78. 